\title{
Percepção dos visitantes do Museu da Geodiversidade sobre o patrimônio geológico ex situ em exposição
}

\author{
Perception OF VISitors to the Museu da Geodiversidade about the eX-SITU geological heritage in eXPosition \\ Renan Gomes Paiva da Silva ${ }^{1}$, Aline Rocha de Souza Ferreira de Castro ${ }^{2}$, Kátia Letite Mansur ${ }^{1}$ \\ 1 - Programa de Pós-Graduaç̃ó em Geologia, Instituto de Geociências, Universidade Federal do Rio de Janelro, RJ, Brasil. \\ 2 - Museu da Geodiversidade, Instituto de Geociênclas, Universidade Federal do Rio de Janeiro, RJ, Brasil.

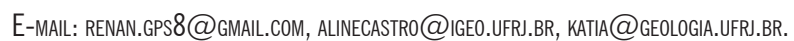

Abstract: Despite the progress of the discussion on geodiversity and geological heritage, since 1990, the lack of production on ex situ geological heritage is still low. The heritage can be inserted in the context of science museums. To understand the relationship between the public of visitors and the protected geological heritage, an opinion survey was applied for considering the population in the museums' elaborations and actions, mainly in their scientific communication strategies. A questionnaire was created, to be filled in by MGeo visitors from the 6th year of elementary school onwards, aiming to analyze 3 aspects: who they are, experience at MGeo and perception and appropriation of geodiversity and geological heritage themes. It was found that the public with the highest response rate was higher education in spontaneous visits and without a mediator. It was possible to notice that there is awareness of the theme, whether for aesthetic, geoscientific and cultural values.

Resumo: Apesar do avanço da discussão sobre geodiversidade e patrimônio geológico, desde 1990, a produção sobre o patrimônio geológico ex situ ainda é considerada baixa. Esse patrimônio pode estar inserido no contexto de museus de ciências. Para entender a relação entre 0 público de visitantes e o patrimônio geológico salvaguardado é preciso realizar pesquisa de opinião, no intuito de incluir a população nas elaborações e ações dos museus, principalmente em suas estratégias de divulgação científica. Para isso foi elaborado um questionário, a ser preenchido pelos visitantes do MGeo a partir do $6^{0}$ ano do ensino fundamental, visando analisar 3 aspectos: quem são, experiência no MGeo e percepção e apropriação dos temas geodiversidade e patrimônio geológico. Verificou-se, que o público com maior índice de respostas foi o de ensino superior em visitas espontâneas e sem mediador. Foi possível perceber que há sensibilização da temática, seja por valores estéticos, geocientíficos e culturais.

\section{Introdução}

A discussão sobre geodiversidade e patrimônio geológico ganha força no movimento conservacionista internacional a partir da década de 1990 e vem sendo desenvolvida e enriquecida por diversos profissionais ao longo dos anos. Entretanto, o número de trabalhos dedicados ao patrimônio geológico ex situ não é expressivo. Van Geert (2020) menciona a baixa na produção acerca do patrimônio geológico ex situ, após uma análise da produção da revista Geoheritage de 2009 a 2019, na qual, dentre 343 artigos publicados, apenas quatro abordam especificamente questões patrimoniais de museus, ainda assim, sem se concentrar na maneira de expô-los.

Castro et al. (2015), em relação ao patrimônio geológico in situ, afirmam que há poucos trabalhos sobre geoconservação que buscam conhecer melhor as comunidades que vivem em contato direto com patrimônio geológico antes de iniciar os
Citation/Citação: Silva, R. G. P. da, Castro, A. R. S. F. de, \& Mansur, K. L., (2021). Percepção dos visitantes do Museu da Geodiversidade sobre o patrimônio geológico ex situ em exposição.. Terræ Didatica, 17(Publ. Contínua), 1-12, e021055. doi: 10.20396/ td.v17i00.8666422.

Keywords: Geological Heritage, Science Communication, Audience, Questionnaire, Museum.

Palavras-chave: Patrimônio Geológico, Divulgação Científica, Público, Questionário, Museu.

\section{Manuscript/Manuscrito:}

Received/Recebido: 23/07/2021

Revised/Corrigido: 11/10/2021

Accepted/Aceito: 15/12/2021

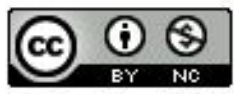

trabalhos de geoconservação, geoturismo, divulgação científica ou educação patrimonial. O mesmo se percebe em relação ao patrimônio geológico $e x$ situ. Este é um universo amplo de pesquisa em que cabe a análise da relação deste patrimônio com os museus e o seu público, em especial, com museus que abordam o tema como narrativa em suas exposições e/ou têm em seu acervo exemplares considerados como patrimônio geológico. As pesquisas de público também contribuem para uma auto análise dos espaços de salvaguarda do patrimônio, sobre suas efetivas ações de comunicação. Mano et al. (2017) declaram que os estudos de público em museus inserem o visitante no processo de organização dos serviços e experiências culturais oferecidos, reconhecendo a legitimidade da expressão do não especialista. Assim, a análise desses estudos pode resultar em estratégias de divulgação científica para esses espaços. 
Este trabalho tem como objetivo analisar, a partir da aplicação de questionários, a percepção do público sobre os temas geodiversidade e patrimônio geológico na exposição "Memórias da Terra" do Museu da Geodiversidade (MGeo) da universidade Federal do Rio de Janeiro (UFRJ). O artigo visa contribuir com a produção acerca de patrimônio geológico $e x$ situ, assim como, fornecer dados capazes de auxiliar o desenvolvimento de atividades e novas abordagens, e servir de subsídio para o planejamento e execução de divulgação científica realizado pela equipe do MGeo.

\section{Patrimônio Geológico ex situ, museus, divulgação científica e pesquisa de público}

Silva et al. (2020) ao realizarem uma breve análise nas propostas geoconservacionistas existentes na literatura, verificaram que o valor patrimonial associado à geodiversidade está presente no cotidiano da vida humana. A partir da análise realizada, percebeu-se que o patrimônio geológico ainda é compreendido pela atribuição de valor geológico a algum bem de natureza material ou imaterial segundo a narrativa geocientífica.

García-Cortés \& Carcavilla Urquí (2013) conceituam patrimônio geológico como o conjunto de formações e estruturas geológicas de valor científico, cultural e/ou educativo, que permitem conhecer, estudar e interpretar a origem e evolução da Terra e da vida, incluindo os processos que o modelaram e climas e paisagens passadas e presentes. Essa tipologia de patrimônio pode ser subdividida em patrimônio geológico in situ ou ex situ (Ponciano et al. 2011, Brilha, 2016), também conhecidos como bens móveis ou imóveis do patrimônio geológico (ASGMI, 2018). A diferenciação conceitual entre eles se dá no local onde o patrimônio é encontrado, se ainda está em seu local de origem (in situ) ou se está fora do local de origem (ex situ). Assim, patrimônio geológico ex situ ou bem móvel do patrimônio geológico pode ser entendido como os elementos de geodiversidade ao qual são atribuídos valores científico, cultural, educativo, entre outros, mas que estão fora de seu local de origem em decorrência de uma ação intencional do ser humano em preservá-los, pesquisá-los ou colecioná-los (Silva, 2020).

Uma vez fora do seu local de origem, a geodiversidade é compreendida como patrimônio ao passar pelo processo de musealização, processo que se inicia, por exemplo, no ingresso dos objetos nos museus. O patrimônio geológico ex situ, quando inserido no contexto de museus, continua seguindo a premissa de atribuição de valor, seja ele científico, cultural, educativo, entre outros, inerente ao processo de musealização ao qual todo objeto passa ao ingressar num espaço museal. Quando o objeto passa a fazer parte de uma narrativa expográfica, ainda no âmbito da musealização, ele necessita de uma contextualização, ou seja, por meio de recursos simbólicos, textuais, imagéticos, audiovisuais, entre outros, se apresenta o ambiente onde ele se encontrava originalmente para facilitar a comunicação, um dos pilares de atuação dessas instituições.

Segundo o International Council of Museums (ICOM) o museu é "uma instituição permanente, sem fins lucrativos, a serviço da sociedade e de seu desenvolvimento, aberto ao público, que adquire, conserva, pesquisa, comunica e expõe o patrimônio tangível e intangível da humanidade e seus ambientes para fins de educação, estudo e apreciação" (ICOM, 2007). Apesar se ser uma definição defasada e que se encontra num longo processo de reformulação, é possível verificar que os museus são locais propícios para se realizar divulgação científica.

Segundo dados do Sistema de Indicadores de Percepção Social - Cultura (IPEA, 2010), 67,9\% da população brasileira não realiza visitas a museus como prática cultural. Os motivos vão desde a organização do espaço à percepção do indivíduo, sobre distribuição dos equipamentos, atividades em tempo-livre, além de variáveis econômicas e sociais. Os números apresentados no estudo podem ser entendidos como relevantes para o alto ou baixo acúmulo de capital cultural e a falta de familiaridade da população com o espaço, fazendo com que esses sejam utilizados sem aproveitamento de sua potencialidade.

Por outro lado, dados da pesquisa Cultura nas Capitais (Leiva \& Meireles, 2018), realizada em 12 capitais brasileiras (Belém, Belo Horizonte, Brasília, Curitiba, Fortaleza, Manaus, Porto Alegre, Recife, Rio de Janeiro, Salvador, São Luís e São Paulo), revelam que $31 \%$ da população possuem o hábito de visitar museus, com espaço amostral de 33 milhões de habitantes, o que é considerada uma porcentagem muito baixa quando comparada a outros hábitos culturais do estudo, como ir ao cinema ou shows de música e ler livros.

Assim, a partir da análise dos dados do IPEA e da pesquisa Culturas nas Capitais, é necessário promover ações que visem à inclusão dos museus como práticas culturais. Uma das ações aponta para a forma como os museus se comunicam com o seu público, pelo desenvolvimento de estratégias de comunicação e divulgação científicas. A divulgação 
científica tem sua importância revelada na aproximação da ciência e seu conhecimento gerado com a população (Paula et al., 2014). Mansur (2009), afirma que os diferentes termos assumidos ao longo do tempo para ações nesse sentido, como por exemplo, vulgarização e popularização, têm a mesma finalidade de "transmitir uma mensagem com conteúdo científico, por meio da decodificação dos termos pouco usuais para uma linguagem acessível ao público leigo".

Observa-se que, em relação ao patrimônio geológico, esteja ele ex situ ou in situ, os museus e a divulgação científica têm um elo em comum que, sem sombra de dúvidas, é a população que vive, atribui valor e é alvo de estratégias das instituições eleitas pela sociedade para salvaguardar o patrimônio geológico. Assim, é preciso conhecer esse público, para que as questões filosóficas sobre o lugar e seus propósitos sejam respondidas (Hooper-Greenhill, 2006); isso pode ser feito a partir de pesquisas de público que abarcam os mais variados temas, desde que estejam relacionados a um espaço museal específico.

A pesquisa de público foi realizada no Museu da Geodiversidade (MGeo), que é um museu universitário de ciências localizado no Instituto de Geociências (IGEO), do Centro de Ciências Matemáticas e da Natureza (CCMN), da Universidade Federal do Rio de Janeiro (UFRJ). Foi criado em 2007, com abertura das portas em 2008, ao inaugurar a sua primeira exposição. Desde o início tem como missão a divulgação das Geociências para a sociedade com foco no patrimônio geológico (Castro et al., 2012). Em 2011 inaugurou a exposição "Memórias da Terra", objeto de estudo deste trabalho, que aborda o conceito de geodiversidade de forma holística, sem desvincular a presença humana e suas marcas sobre a memória do planeta (Diogo \& Silva, 2018).

O circuito expositivo é formado por 13 módulos que contam a história de evolução do planeta e da vida na Terra com a exposição de um diversificado acervo próprio e outros em comodato, como os meteoritos, onde se destacam os fragmentos do famoso Bendegó, um dos primeiros meteoritos de composição metálica a ser reconhecido no mundo, além de ser o primeiro encontrado no Brasil, mais especificamente na Bahia, em 1784. Também estão em exibição minerais comuns e raros, como feldspato, mineral mais comum da superfície terrestre e a crocoita, óxido de chumbo e cromo da Tasmânia. Também existem fósseis e icnofósseis na exposição que são essenciais para entender e contextualizar a história de evolução da vida na Terra, como o estromatólito Jurussania, de Irecê, Bahia, datado de $1.2 \mathrm{Ga}$; o Baurusuchus salgadoensis, espécie de réptil predador que viveu no período Cretáceo e habitava a região da Bacia Bauru, no estado de São Paulo; e uma grande quantidade de fósseis do Grupo Santana, Bacia do Araripe, que devido a sua preservação extraordinária e diversidade dos organismos é considerada como Largerstätten.

As reconstituições também merecerem destaque, pois propiciam a imersão do visitante à temática proposta pela sala. As reconstituições não são réplicas, são paleoartes que buscam retratar os organismos, seja em esqueleto ou completo, em posição de vida. São itens únicos desenvolvidos por meio da união entre arte e ciência. Estão em exposição o dinossauriforme Sacisaurus agudoensis, do Triássico, Formação Caturrita, Bacia do Paraná, RS e o mais antigo espécime de dinossauro Saturnalia tupiniquim, também do Triássico, Formação Santa Maria, Bacia do Paraná, RS, entre outros. O acervo exposto é contextualizado mediante emprego de recursos museográficos, que fazem ambientações: as reconstituições representam os ambientes pretéritos ou eventos abordados pela sala. Aparatos interativos também fazem parte dos recursos presentes na exposição, como a simulação de terremoto, jogos e vídeos.

A divulgação do museu foi se ampliando ao longo do tempo e o número de interessados em conhecer a exposição está aumentando como pode ser observado pelo crescente número de visitantes nos anos de 2016, 2017, 2018 e 2019, quando a exposição recebeu, respectivamente, $4.721,5.660,7.356$ e 9.304 visitantes, segundo os relatórios de frequência de visitação. Dos números, boa parte é de instituições de ensino básico (públicas e privadas) com maior expressividade no nível fundamental. Em 2018 houve um aumento de visitas por grupos de instituições de nível superior, principalmente no $1^{\circ}$ semestre. $O$ fato pode ser atribuído à inauguração, nesse semestre, da sala "Gondwana: a Terra em movimento".

Em 2013, Aracri (2013) realizou uma pesquisa de opinião no MGeo, relativa à percepção dos professores que o visitaram acompanhando seus alunos. $\mathrm{Na}$ dissertação, a autora conclui que a forma como os professores de ensino formal utilizam os espaços está ligada ao seu acúmulo de capital cultural, levando-os a utilizar o espaço muitas vezes só para complementar os temas abordados em sala de aula, sem perceber toda a potencialidade de mudança social que os museus possuem. Esta pesquisa apresentou um recorte específico, sendo necessários outros estudos para se contemplar a percepção daquele espaço na visão de outros tipos de visitantes, como os alunos, por exemplo.

\begin{tabular}{c|c|c|c|c|c}
\hline (C) Terrae Didat. & Campinas, SP & v.17 & $1-12$ & $\mathrm{e} 021055$ & 2021 \\
\hline
\end{tabular}




\section{Pesquisa de opinião no MGeo}

A pesquisa de opinião é uma ferramenta de análise qualitativa. Para o trabalho, foi escolhido o modelo metodológico de questionários, que de acordo com Gil (1995) é "uma técnica de investigação composta por um número mais ou menos elevado de questões apresentadas por escrito às pessoas, tendo por objetivo o conhecimento de opiniões, crenças, sentimentos, interesses, expectativas, situações vivenciadas etc.". Vale ressaltar que a seleção dos itens pesquisados e a análise também levaram em consideração a experiência dos autores sobre o MGeo e sobre o público que o frequenta, baseada em atuações como bolsista mediador, museóloga e diretora do museu.

O questionário desenvolvido teve como referência a experiência relatada por alguns pesquisadores que descrevem diferentes metodologias e experiências de aplicação e análise de questionários, seja para pesquisas em museus ou não, tendo em comum os temas relacionados a pesquisa de público e percepções sobre algum assunto específico (Aracri, 2013, Castro et al., 2015, Mano \& Damico, 2017, Mano et al., 2017).

O público alvo que a pesquisa atingiu foi o de visitantes que o museu recebe, abrangendo visitas agendadas ou espontâneas, com ou sem mediação. Participaram indivíduos que possuíam escolaridade acima do $6^{\circ}$ ano do ensino fundamental, pois é a partir desse nível escolar que os visitantes são considerados aptos para responderem o questionário sem auxílio de mediador e é nesse período escolar que o ensino de Geociências é incluído no currículo.

Antes da aplicação, houve um período de testes com o acompanhamento do pesquisador, cuja finalidade foi identificar possíveis irregularidades dos protótipos, e assim, produzir a versão final utilizada (Fig. 1). Os questionários ficaram disponíveis para preenchimento de novembro de 2018 até novembro de 2019 e foram alocados ao final da exposição, próximo a uma urna, junto a uma caneta e um cartaz com informações sobre a pesquisa de opinião.

O questionário foi elaborado para que os respondentes preenchessem de forma rápida e autônoma. Os visitantes foram avisados e convidados a participar da pesquisa pelos integrantes da equipe do MGeo, antes de iniciarem a visita ou ao final, sendo o preenchimento facultativo. Ele foi pensado em 3 blocos de perguntas: (1) conhecendo o visitante, (2) experiência no museu e (3) compreensão do tema. Esses blocos são compostos por questões de livre resposta e resposta condicionada. Assim, o questionário trata do patrimônio geológico contido na exposição, na perspectiva de estudar o público que a visita em termos de sua interação com esse patrimônio e a percepção que obtiveram dos temas abordados após a visita à exposição. A seguir se encontra a discriminação e descrição das questões elaboradas para cada bloco.

\section{Conhecendo o visitante}

No primeiro bloco de perguntas entende-se que os fatores de idade (Borges, 2008), grau de escolaridade e a frequência de visitas a espaços culturais podem resultar no grau de compreensão do tema abordado, além das diferentes leituras dos tipos de linguagem utilizadas no museu. Logo, destinou-se a conhecer melhor esse público com informações de sexo, idade, grau de escolaridade, vínculos institucionais, frequência de visitas a espaços culturais e até mesmo se o visitante já tinha visitado o MGeo outras vezes.

Nesse bloco a questão "Como sua visita ao museu foi feita?" se fundamenta nos tipos de visitas possíveis ao espaço. Logo, essa questão almeja entender como esses tipos de visitas se relacionam com a compreensão do tema por parte do público, ou seja, como visitas sejam mediadas ou autônomas vão impactar a fruição pelo espaço. Saber a frequência de visitas a espaços culturais, se mostra pertinente quanto ao interesse do público por espaços museais, bem como a quantidade de vezes que o respondente visitou o MGeo.

\section{Experiência no MGeo}

Para segundo bloco, entende-se que é essencial saber a opinião do visitante sobre a exposição e sua experiência dentro do espaço.

O bloco de questões conteve cinco perguntas de respostas condicionadas e duas perguntas de livre resposta. As condicionadas visaram saber a opinião do visitante sobre o museu, quanto à qualidade dos textos, limpeza, organização, com seis opções de resposta que conceituam o grau de satisfação dos visitantes sobre um determinado aspecto da visita. As questões de livre resposta visaram avaliar a percepção do visitante sobre: o papel do mediador, o museu e os objetos expostos.

\section{Compreensão do tema}

O terceiro bloco foi direcionado para identificar se o tema abordado pelo museu foi assimilado ou se o visitante se sensibilizou pelo tema. Nesse bloco as questões variam, contendo uma pergunta de resposta condicionada ('sim' e 'não'), para saber 
se os visitantes já conheciam os conceitos abordados na exposição. Há também uma questão que utiliza caixas de seleção, na qual as palavras escolhidas para a percepção de geodiversidade foram pensadas de acordo com o conceito de Gray (2013), para quem a geodiversidade corresponde aos produtos e processos abióticos do planeta que proporcionam serviços à vida. Assim, foram selecionados os termos fóssil, montanha, dunas, ferro, paisagem, rocha, praia, meteorito, areia, pintura rupestre, mineral, planeta Terra, petróleo, formação do solo e água.

Também foi elaborada uma questão na qual os itens condicionados a escolhas deveriam ser classificados em um sistema de ranking. Nessa pergunta aborda-se a percepção de patrimônio geológico e sua significância. Portanto, foram selecionadas algumas palavras as quais se pode associar o valor patrimonial, tendo como base a lista de bens tombados pelo Instituto do Patrimônio Histórico e Artístico Nacional (IPHAN) (2018), como patrimônio natural que possuem elementos geológicos facilmente reconhecidos, independentemente de este ser o motivo de seu tombamento; o livro "Geoparques do Brasil - Propostas" (Schobbenhaus \& Silva, 2012) e; até mesmo, algumas peças contidas na exposição. Assim, estão inclusos na lista, Pão de Açúcar, Baía de Guanabara, floresta petrificada,

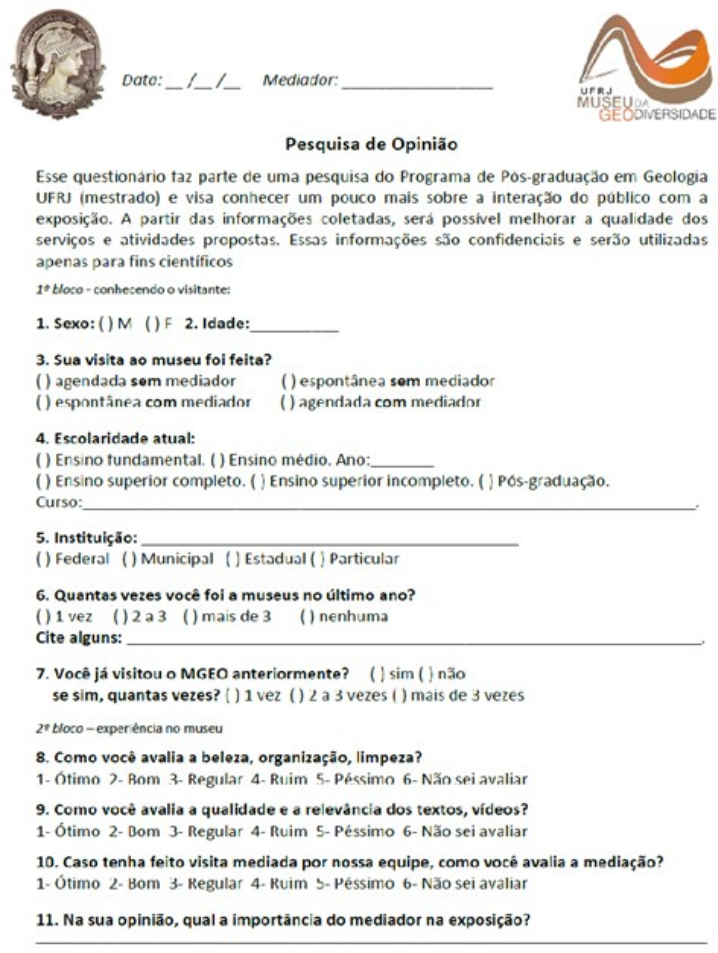

ametista, água, rochas, animais, plantas, paisagens, Praia do Arpoador, fósseis de dinossauros, flor, mina desativada e meteorito Bendegó. Foi solicitado que dentre as palavras escolhidas os visitantes atribuam um grau de relevância às peças, onde "A" representa um alto grau de relevância, " $M$ " médio grau, "B" baixo e "N" nenhum.

Ao final do questionário foram dispostas duas perguntas de livre resposta: em uma delas questiona-se a importância da geodiversidade para a sociedade. A última questão se destina a comentários, críticas e sugestões dos visitantes sobre qualquer aspecto do museu.

\section{Análise dos questionários}

A análise do questionário ocorreu da seguinte forma: $1^{a}$ etapa - compilação dos dados, que consistiu em recolher os questionários das urnas, analisar a validade dos questionários respondidos e tabelar os dados no Microsoft Excel @; $2^{\mathrm{a}}$ etapa - análise dos dados, etapa de leitura, confecção de gráficos e interpretação dos dados gerados.

A etapa de compilação de dados se iniciou com uma classificação dos questionários, os qualificando como válidos e não-válidos. Foram considerados válidos aqueles que apresentaram respostas completas principalmente no $3^{\circ}$ bloco
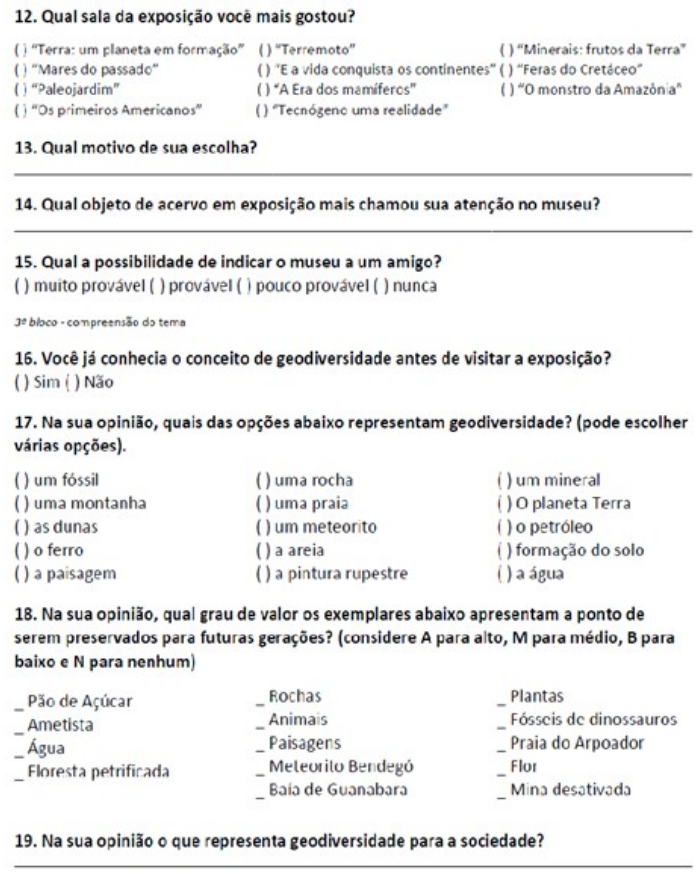

19. Na sua opinião o que representa geodiversidade para a sociedade?

20. Deixe aqui algum comentário, críticas e sugestões:

Figura 1 Frente e verso da versão final do questionário aplicado aos visitantes

\begin{tabular}{c|c|c|c|c|c}
\hline (C) Terrae Didat. & Campinas, SP & v.17 & $1-12$ & $\mathrm{e} 021055$ & 2021 \\
\hline
\end{tabular}


de perguntas, uma vez que esse é o principal bloco gerador de dados para o trabalho. Após essa etapa, foi feita a tabulação de dados dos questionários válidos. Para tal, foi criado um formulário online no Google Forms ${ }^{\circledR}$ com as mesmas questões do questionário impresso. Todas as respostas obtidas nos questionários válidos foram transpostas para a plataforma online. A plataforma elabora gráficos automaticamente a partir das informações inseridas e esses dados por ser exportados para uma planilha como o Microsoft Excel $®$, permitindo uma melhor análise estatística (Mano \& Damico, 2017). Para as questões de resposta livre foi utilizado o método gráfico de Nuvens de Palavras, utilizando o software Word Cloud Generator ${ }^{\circledR}{ }^{121}$ (Mano \& Damico, 2017), que permite a comparação entre termos que se repetem nas respostas, nos dando uma interpretação quantitativa da pesquisa de opinião.

\section{Resultados}

Os questionários ficaram disponíveis ao público durante 13 meses. Ao longo desse período foram impressos 200 questionários. Desse universo, 148 foram preenchidos e devolvidos à urna, localizada na saída do espaço expositivo. O destino dos 52 questionários que não voltaram para análise é desconhecido. Como estabelecido na metodologia, esses 148 questionários foram inicialmente analisados quanto sua validade e posteriormente transcritos para o Google Forms. Dessa forma, foram considerados 102 questionários válidos e 46 foram descartados.

Quanto ao sexo e idade dos respondentes, $67,6 \%$ se autodeclararam do sexo feminino e $32,4 \%$ do sexo masculino. As idades variaram de 10 a 65 anos, com maior expressividade na faixa entre $18 \mathrm{e}$ 21 anos. O grau de escolaridade dos participantes da pesquisa indica que: $61,4 \%$ possuem nível superior incompleto, $14,9 \%$ nível superior completo, $13,9 \%$ estão no ensino médio, $4 \%$ no ensino fundamental e $5,9 \%$ na pós-graduação.

Quando questionados sobre a forma que realizaram a visita, $80,2 \%$ responderam que realizaram a visita de forma espontânea sem mediador, 9,9\% agendada com mediador, 6,9\% espontânea com mediador e 3\% agendada sem mediador (Fig. 2). Então, é possível afirmar que os dados que foram analisados são de pessoas que escolheram visitar a

10 software foi utilizado em todas as respostas de "livre resposta" contidas no questionário e está disponível no sítio: https://www.jasondavies.com/ wordcloud/. Acessado em março de 2020.

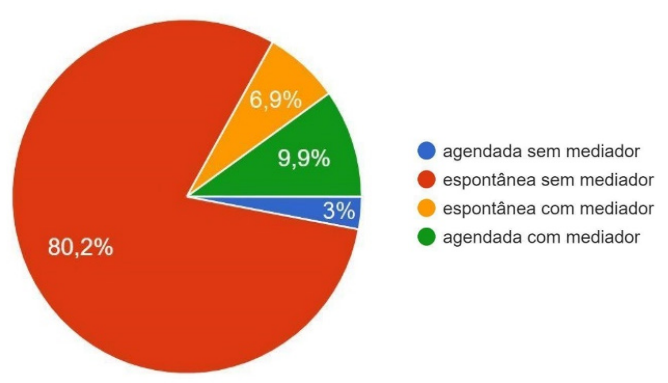

Figura 2. Gráfico informativo sobre forma de visitação ao museu. Pergunta: de que forma foi feita sua visita ao museu? (101 respostas)

exposição de forma autônoma e possuem fonte de informação os textos, acervos e recursos museográficos adotados, sem as informações adicionais que uma visita conduzida por um mediador propicia. Desta forma, os resultados poderão evidenciar como está ocorrendo a comunicação da exposição com o público, sem intermediação.

$\mathrm{O}$ vinculo institucional dos respondentes foi majoritariamente da esfera federal, com 70,3\% (Fig. 3 ), e estavam ligados diretamente a universidades públicas com grande expressividade de vínculo com a UFRJ. Desta forma, é possível aferir que a maior parte dos visitantes espontâneos do Museu da Geodiversidade possui algum vínculo com a UFRJ, e que, em sua maior parte, são alunos.

Quando questionada a frequência de visitas a museus no último ano (entre 2018 e 2019), 40,2\% dos respondentes afirmaram visitar outras instituições de ' 2 a 3 vezes', 25,5\% estiveram 'mais de 3 vezes' em outros museus, $18,6 \%$ assinalaram ter ido ' 1 vez' e $15,7 \%$ 'nenhuma vez'. Os museus mais citados foram o Centro Cultural Banco do Brasil (CCBB), Museu de Artes do Rio (MAR) e Museu do Amanhã. Foi possível observar que uma boa quantidade de visitantes foi ao Museu Nacional até meados de 2018,

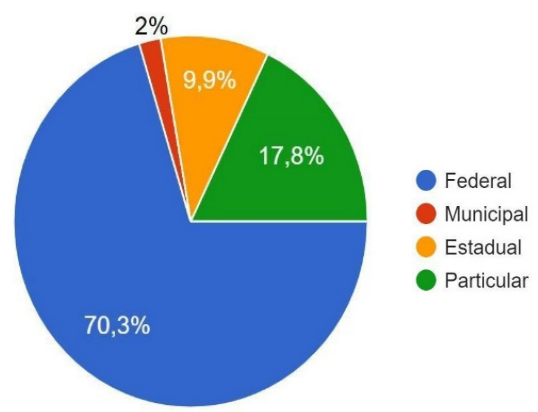

Figura 3. Gráfico informativo quanto ao tipo de instituição à qual o visitante é vinculado (federal, municipal, estadual ou privada). Pergunta: qual tipo de instituição? (101 respostas) 
quando ocorreu o incêndio (setembro). Assim, no ano de 2019 esse museu não foi citado. Alguns visitantes afirmam já ter visitado o MGeo anteriormente, totalizando $68,6 \%$ dos respondentes, dos quais $53,1 \%$ visitaram o MGeo apenas uma vez, 28,1\% de 2 a 3 vezes e $18,8 \%$ mais de 3 vezes.

Os resultados sobre a experiência dos visitantes ao espaço expositivo estão apresentados na Figura 4: em grande maioria, o público que visita a exposição considera que a beleza, organização e limpeza, qualidade e relevância dos textos e vídeos e a mediação, quando realizada por algum membro da equipe do museu, são ótimos. Entretanto, é importante destacar que um número significativo de participantes não respondeu às questões referentes à mediação, com apenas 46 respostas em um universo de 102 questionários válidos. Isso pode ter acontecido porque a maior parte dos respondentes visitou o espaço museal de forma espontânea e sem mediador, por isso, não saberiam responder sobre esse tema. A partir desses dados, mesmo que a visita não tenha sido mediada, é possível afirmar que existe um reconhecimento da importância do papel do mediador para o espaço, na medida que, nas respostas livres, o visitante identifica que o mediador exerce a função de "desmistificar", "esclarecer", "ajudar a entender, "explicar" o tema abordado pela exposição, como revela a nuvem de palavras da Figura 5.

Ao serem questionados sobre a sala que mais despertou interesse ao longo da exposição a "Minerais: frutos da Terra" foi a mais mencionada, seguida da sala "Feras do Cretáceo (Fig. 6). O aparente motivo de escolha das salas pode ser atribuído à tendência de incorporar valores pessoais às escolhas, com grande índice de valores estéticos e baixo índice de valores científicos, como pode ser visualizado no gráfico
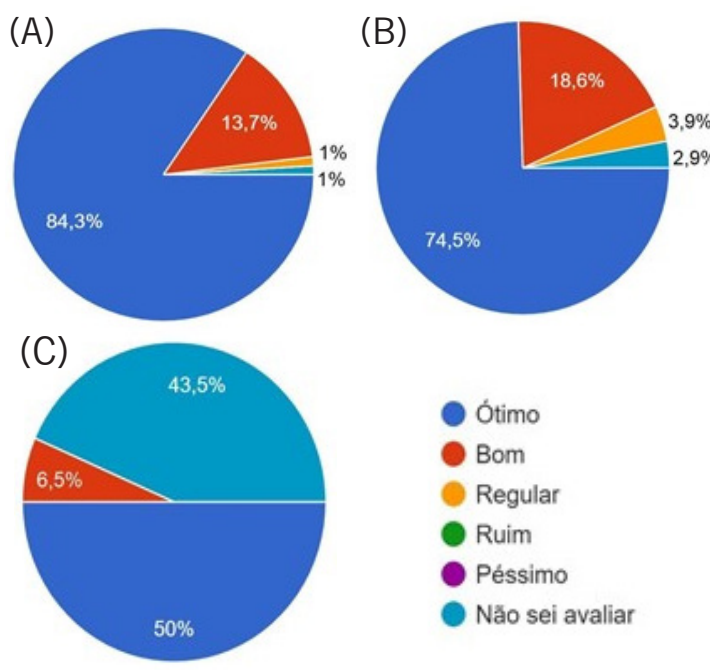

Figura 4. Gráficos em pizza das três primeiras questões relacionadas ao segundo bloco de perguntas, sobre a experiência do público durante a visita. Perguntas: (A) Como você avalia a beleza, organização, limpeza? (102 respostas); (B) Como você avalia a qualidade e a relevância dos textos, vídeos? (102 respostas); (C) Caso tenha feito visita mediada por nossa equipe, como você avalia a mediação? (46 respostas)

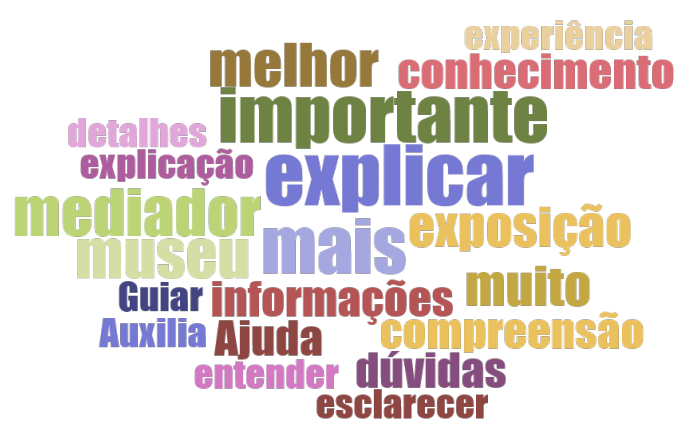

Figura 5. Nuvem de palavras com opinião dos visitantes sobre a importância do mediador

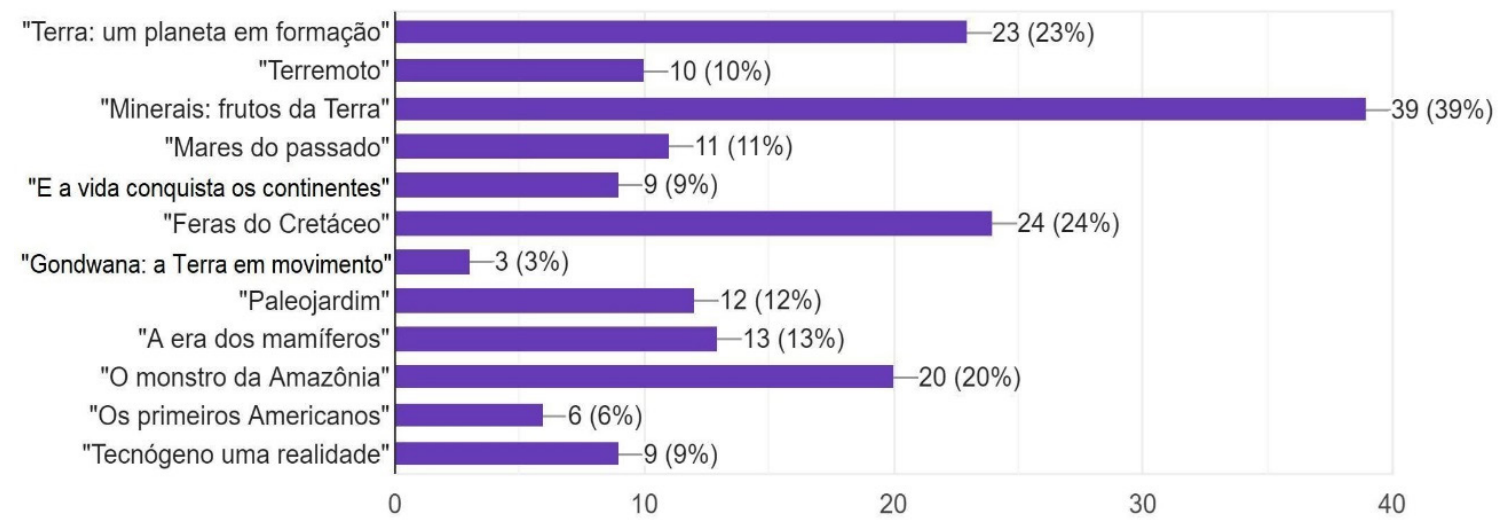

Figura 6. Gráfico informativo das salas de preferência dos visitantes. Pergunta: de qual sala da exposição você mais gostou? (100 respostas) 
de nuvem de palavras (Fig. 7). Esse resultado é importante para corroborar a relevância de outros valores relacionados ao patrimônio geológico, principalmente quando se pensa na comunicação com a sociedade.

A nuvem de palavras (Fig. 8) indica qual peça do acervo exposto mais chamou atenção dos visitantes, durante sua fruição pelo espaço expositivo. Fica evidente que os fósseis, principalmente os que representam dinossauros, são preferência, mas os minerais também são representativos. Então, na condição de acervo, os fósseis, em especial os dinossauros, são os que despertam maior interesse, porém quando pensamos no conjunto, considerando o acervo e a museografia, a preferência foi a parte de minerais, conforme mostra a figura 7. É importante destacar que a maior parte dos dinossauros que estão na exposição são reconstituições e não fósseis, que também estão representados em imagens contextualizadas em ambientes pretéritos e em posição de vida,

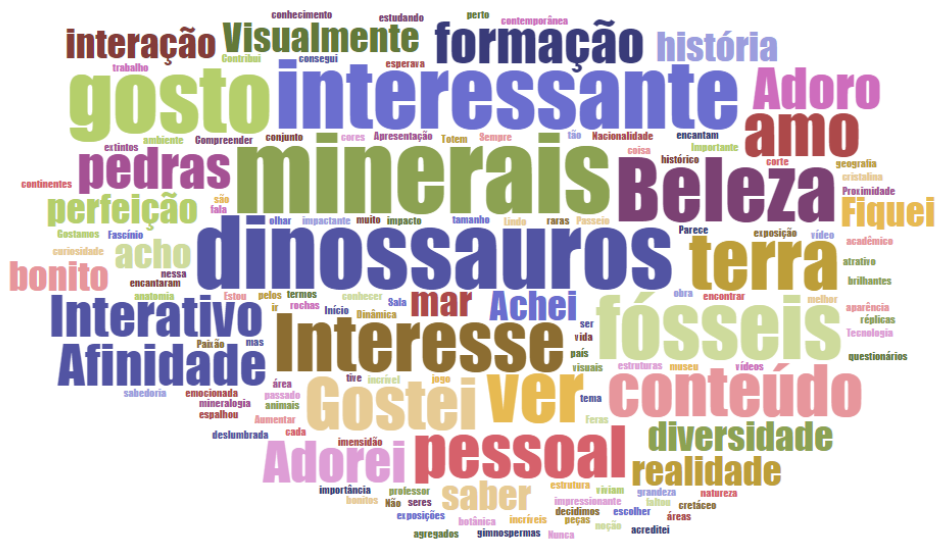

Figura 7. Nuvem de palavras com motivo de escolha das salas de preferência

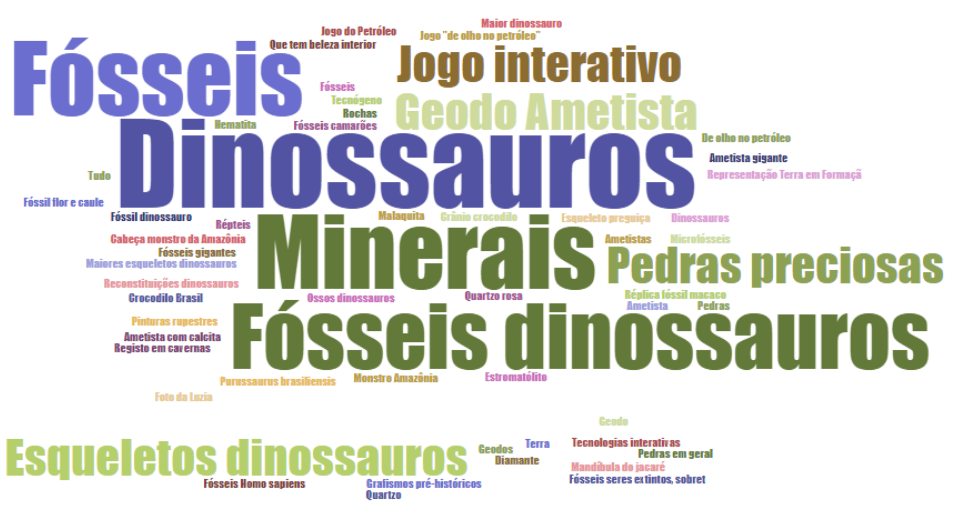

Figura 8. Nuvem de palavras com objetos de acervo de preferência dos visitantes que são denominadas de paleoartes. Assim, quer em duas dimensões, quer em três dimensões, o trabalho interdisciplinar entre o cientista e o artista é de grande relevância para a comunicação com o público em um museu e, quando são peças únicas ou feitas em série, também podem vir a ser consideradas patrimônio.

Muitos entrevistados (87,3\%) afirmaram que "muito provavelmente" indicarão o MGeo aos amigos, de modo que é possível concluir que a experiência no museu foi boa. Apenas 11,8\% mencionaram que a indicação seria "provável", $1 \%$ "pouco provável" e não houve entrevistados que afirmassem que nunca indicariam o museu para os seus amigos.

Segundo os dados obtidos, o conceito de "geodiversidade" já era conhecido por mais da metade dos respondentes (59,6\%). Esse resultado mostra que o conceito está cada vez mais presente na sociedade, porém, pode ser sido alto porque a maior parte dos entrevistados possui algum vínculo com a UFRJ, já tendo contato com o termo em seus cursos ou pelo próprio nome do museu.

A percepção do público sobre o conceito de geodiversidade e patrimônio geológico, assim como sobre quanto o museu sensibiliza e permite apropriação dos conceitos pelo público, esteve representada por respostas positivas, quando analisados os dados do terceiro bloco do questionário. Nele foi solicitado aos entrevistados que indicassem quais elementos poderiam ser considerados como geodiversidade. Foram disponibilizadas como opções de respostas as palavras: fóssil, rocha, mineral, montanha, praia, Planeta Terra, dunas, meteorito, petróleo, ferro, areia, formação do solo, paisagem, pintura rupestre e a água. Dentre as palavras mencionadas com maior frequência pelos entrevistados estão os fósseis, as rochas e o Planeta Terra (Fig. 9).

A Figura 10 representa a percepção dos visitantes sobre patrimônio, percebido pela atribuição de grau de relevância aos elementos do patrimônio elencados no questionário. Os visitantes mostraram que possuem preferência e empatia por alguns dos elementos da natureza a serem preservados para futuras gerações, dentre os quais a água, os 


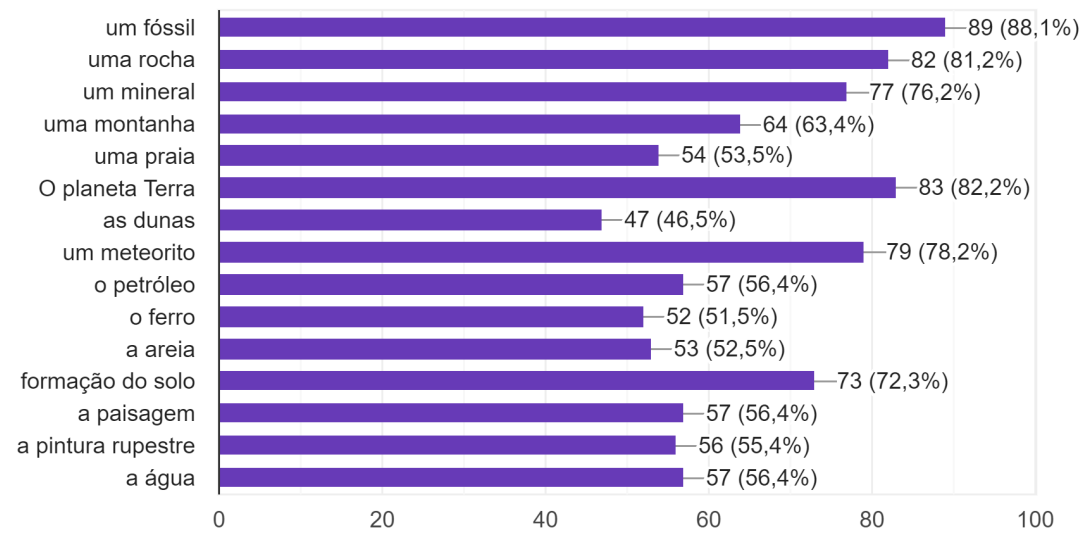

Figura 9. Gráfico de elementos que representam a geodiversidade, conforme os visitantes, para a pergunta: na sua opinião, quais das opções abaixo representa geodiversidade? (é possível escolher mais de uma opção)

animais, as plantas e os fósseis de dinossauros são os elementos do patrimônio que mais possuem relevância e a mina desativada é a que tem menos relevância para preservação.

A última questão, referente à percepção do público, tratou da importância da geodiversidade para a sociedade. Das respostas obtidas elencaram-se algumas que se destacam na comprovação de que parte
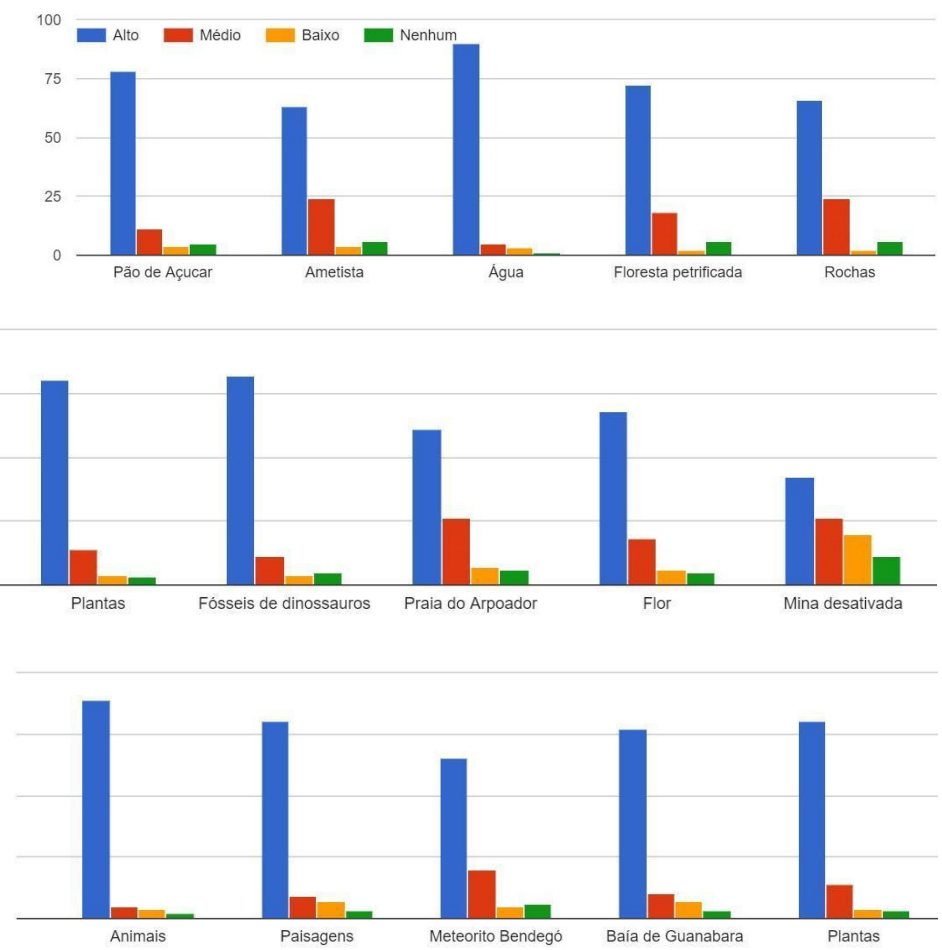

Figura 10. Gráficos de ranking patrimonial indicados pelos visitantes. Pergunta: na sua opinião, qual grau de valor os exemplares abaixo apresentam para serem preservados para futuras gerações? (considere A para alto, M para médio, B para baixo e $\mathrm{N}$ para nenhum) dos visitantes ao fruírem pela exposição "Memórias da Terra" se sensibiliza e capta a mensagem de disseminar e valorizar a vertente abiótica da natureza e assim preservá-la. Abaixo algumas das respostas apresentadas pelo público.

"História e cultura como um todo"

"Acredito que ela tem papel essencial na construção do meu senso de pertencimento e memória social. Através da geodiversidade as pessoas podem ter acesso de forma cultural, como no museu, a conhecimentos científicos importantes. Através da geodiversidade podemos conhecer para proteger"

"Entender a formação e a evolução da terra e o que podemos dela usufruir"

"Autoconsciência"

"Podemos entender melhor a dinâmica do nosso processo evolutivo"

"Infelizmente esse conceito é muito importante, mas pouco explorado. Se soubéssemos a verdadeira importância da Terra não erraríamos tanto"

\section{"Conhecimento e história do planeta"}

"Geralmente associam a geodiversidade a "pedras" e nada mais, quando é muito mais do que isso"

"Representa o estudo da diversidade geológica da Terra não só no passado, mas no presente podendo também inferir no futuro"

\section{Discussão}

A partir dos dados levantados foi possível fazer uma correlação direta entre o público que visita a exposição e o público que respondeu a pesquisa. O público que mais visita o museu é aquele em idade escolar, mas foram poucas as respostas deste nicho. Isso pode ter acontecido porque as pessoas em idade escolar estão inseridas no contexto de visitação agendadas

\begin{tabular}{c|c|c|c|c|c}
\hline (C) Terrae Didat. & Campinas, SP & v.17 & $1-12$ & $\mathrm{e} 021055$ & 2021 \\
\hline
\end{tabular}


com mediação da equipe do museu, o que faz com que estabeleçam uma relação de grupo/coletiva com aquele espaço e não individual, como acontece com o visitante espontâneo. A indisponibilidade de tempo é outra questão que pode ter influenciado, pois as visitas mediadas demoram mais e, muitas vezes, ocupam todo o tempo disponível, e o grupo precisa retornar à escola.

O público que mais respondeu a pesquisa foi de nível superior, principalmente que está cursando a graduação. Outro fato relevante é que o público que mais respondeu ao questionário realizou sua visita de forma espontânea e sem mediador. Esses fatos podem ser explicados por dois principais motivos identificados, um deles é o intuito de visitação pública e outro o tempo de permanência dentro do espaço expositivo.

O público de nível superior também pode visitar o museu por intermédio de uma disciplina e solicitar a presença de um mediador. Entretanto, segundo os dados levantados, o público universitário fez sua visita majoritariamente de forma espontânea. Isso pode mostrar que este público, quando realizou uma visita mediada, não optou por responder o questionário e/ou pode mostrar que o espaço é utilizado por diversos motivos para além de ter acesso à informação geocientífica, como, por exemplo, a busca por um espaço de lazer, relaxamento e reflexão, entre os intervalos das disciplinas. Ou seja, eles se sentem à vontade naquele espaço e possuem tempo hábil para responderem a pesquisa.

Quando questionados sobre a frequência de visita a museus no último ano, é possível observar que dentro dos museus visitados, os que abordam a temática geocientífica é raro, os de ciências muito pouco frequente e os de artes são os mais citados. Mostrado que o trabalho de divulgação científica no sentido de captação desse público para o tema ainda tem muito a percorrer. O público se mostrou satisfeito ao avaliar o espaço e as estratégias de divulgação científica utilizadas pelo MGeo.

O patrimônio geológico ex situ exposto no MGeo é diverso. Da mesma forma, é igualmente diversificada a percepção que o público tem do mesmo, ou a forma de identificação e valor atribuído a ele. $\mathrm{O}$ museu consegue sensibilizar o público por meio de ferramentas museográficas e educativas, na medida em que os visitantes, mesmo realizando a visita sem mediação, conseguem identificar a narrativa apresentada, considerando as respostas às questões do $3^{\circ}$ bloco de perguntas destinadas à compreensão do tema. Nessa perspectiva, destaca-se o entendimento dos conceitos de geodiversidade e patrimônio geológico pelos visitantes, fato que revela existir um diálogo do público com o patrimônio geológico ex situ exposto. Entretanto, é possível observar que nem todos os elementos elencados como representativos da geodiversidade foram reconhecidos. Os fósseis, as rochas, os minerais, formação do solo e o planeta Terra apresentam maiores índices de reconhecimento, apesar de o planeta ultrapassar o conceito de geodiversidade, porque envolve aspectos bióticos também. Entre os mais baixos estão o petróleo, o ferro e a água.

$\mathrm{Na}$ pergunta sobre a preservação para futuras gerações, ponto focal do conceito de herança e patrimônio, destacaram-se como os mais valiosos, os animais, plantas, fósseis e água. Este último, apesar de ser reconhecido como elemento a ser preservado, está em percentual mais baixo como representativo de geodiversidade. Os fósseis aparecem em maiores proporções, comprovando que eles estão no imaginário de quem visita o museu, principalmente quando se referem a dinossauros.

Também pode ser somado à discussão o fato de apenas 61 dos 102 respondentes opinarem quando questionados sobre a importância da geodiversidade para a sociedade, dentro desse universo de opiniões; alguns atribuem a geodiversidade à base para o desenvolvimento da vida na Terra.

A palavra "minerais" aparece em grande tamanho na nuvem de palavras, assim como "dinossauros". Na análise do gráfico e da nuvem de palavras referente à resposta da sala que mais gostaram e o motivo de escolha das mesmas, destaca-se que a sala intitulada "Minerais: frutos da Terra" como a mais citada. Os minerais aparecem em destaque como motivo de escolha, além de ser perceptível que o valor estético está muito presente no discurso do visitante para preferência. A palavra "dinossauros" também se destaca no motivo de escolha, entrando em concordância com a segunda sala mais citada como preferida, "Feras do Cretáceo", que conta apenas com as réplicas e reconstituições de dinossauros para apresentação da narrativa.

Outro fato essencial a ser destacado é que ao longo da exposição os dinossauros estão presentes na forma de réplicas ou reconstituições, que para esta pesquisa não se configuram como patrimônio geológico ex situ e sim patrimônio cultural científico e tecnológico. Assim, fica claro que essas ferramentas museográficas são de suma importância para a narrativa contada pelo MGeo e que, ainda, auxiliam no processo de divulgação científica, assim 
como, os jogos interativos ao longo da exposição, que também são muito citados.

\section{Conclusões}

A inclusão da narrativa geocientífica dentro das questões patrimoniais tem avançado com o passar do tempo. Identificar essa tipologia de patrimônio significa permitir a inclusão de uma nova categorização para se chegar a uma visão holística de mundo, no que diz respeito à preservação e conservação da memória da Terra e da humanidade. A presente pesquisa contribui para as discussões acerca de sistematização e reafirmação da importância da nova categoria de pensamento. Principalmente por tratar do patrimônio geológico ex situ que ainda apresenta poucas discussões nos planos nacional e internacional, sobretudo ao ser comparado à produção científica do patrimônio geológico in situ. A relação entre patrimônio geológico e museus é antiga, entretanto, só recentemente ela tem sido inserida no debate científico. Logo, se torna também um novo campo de atuação para a Museologia, as Geociências e a Patrimoniologia.

O geocientista se ocupa principalmente da coleta e pesquisas científicas das amostras. Contudo, ao entrar no contexto museal, o patrimônio geológico ex situ passa a ter uma atenção mais detalhada do museólogo, historiador, arquivologista, biblioteconomista, pesquisador da área de interesse, que podem ser responsáveis pela curadoria do material. Já na exposição, contam também com divulgadores científicos, educadores, designers, que fornecem informações sobre os objetos expostos. Entretanto as funções não são estritamente específicas a um profissional; a equipe deve trabalhar em conjunto para atingir os objetivos.

O MGeo cumpre seu papel fundamental de preservação da memória da Terra, uma vez que é uma instituição que se dedica à pesquisa, conservação e divulgação do patrimônio em sua vertente geológica. A pesquisa de público realizada se mostra pertinente e ratifica a importância da divulgação científica realizada no âmbito do MGeo.

\section{Agradecimentos}

Agradecimentos à CAPES pelo apoio financeiro para o desenvolvimento desta pesquisa no Museu da Geodiversidade (IGeo/UFRJ), bem como a equipe do museu. Este trabalho é parte da pesquisa relativa à dissertação de mestrado do primeiro autor, realizada no Programa de Pós-Graduação em Geologia (PPGL) da Universidade Federal do Rio de Janeiro.

\section{Referências}

Aracri, E. M. R. P. (2013). Professores no Museu da Geodiversidade: o capital cultural nas percepções e expectativas da relação museu x escola. Departamento de Educação, Pontifícia Universidade Católica do Rio de Janeiro. 160p. (Dissert. Mestrado).

Asociación de Servicios de Geología y Minería Iberoamericanos (ASGMI). (2018). Metodología de valoración del patrimonio geológico. 1er Taller de Patrimonio de la ASGMI. Salta, Argentina.

Borges, K. R. (2008). Experimentos interativos: preferências de alunos segundo faixa etária. In: Borges, R. M. R., Mancuso, R., \& Lima, V. M. R. (Orgs.). (2008). Museu interativo: fonte de inspiração para a escola. 2 ed. Porto Alegre: ediPUCRS. Cap. 2, p. 21-26.

Brilha, J. (2016). Inventory and quantitative assessment of geosites and geodiversity sites: a review. Geoheritage, 8, 119-134. doi: 10.1007/s12371-014-0139-3.

Castro, A. R. S. F., Greco, P. D., Mansur, K. L., Pereira, E. M. R., Diogo, M. C., \& Carvalho, I. S. A. (2012). Museografia como ferramenta para a divulgação das Geociências: a experiência do Museu da Geodiversidade (MGEO/IGEO/UFRJ). In: Henriques, M. H. , Andrade, A.I., Quinta-Ferreira, M. Lopes, F. C., Barata, M. T., Reis, R. P. dos, \& Machado, A. (Orgs.). (2012). Para Aprender com a Terra: memórias e notícias de Geociências no espaço lusófono. Coimbra: Universidade de Coimbra. v. 2, p. 185-193. doi: 10.14195/978-989-26-0533-3_19.

Castro, A. R. S. F., Mansur, K. L. \& Carvalho, I. S. (2015). Diagnóstico da relação da comunidade com o patrimônio geológico por meio de instrumento de coleta de dados. Terree Didatica, 11(3), 162-172. doi: 10.20396/td.v11i3.8643644.

Diogo, M. C. \& Silva, R. G. P. (2018). Visitas mediadas no Museu da Geodiversidade: um roteiro sobre patrimônio geológico. In: Lima, J. C. P. (Org.) (2018). Identidade e Pertencimento: a cidade como construção de sociabilidades. São Paulo: Pontocom. Cap. 2, p. 25-38. ISBN: 978-85-66048-94-0.

García-Cortés A, Carcavilla Urquí LC. (2013). Documento Metodológico para la elaboracion del inventario espanñol de lugares de interés geológico (IELIG). Madrid: Instituto Geológico y Minero de España.

Gil, A. C. (1995). Métodos e técnicas de pesquisa social. 4 ed. São Paulo: Atlas.

Gray, M. (2013). Geodiversity: valuing and conserving abiotic nature. John Wiley and Sons.

Hooper-Greenhill, E. (2006). Studying visitors. In: MacDonald, S. (2006). A Companion to Museum Studies. West Sussex: Blackwell. p. 362-376.

Instituto de Pesquisa e Estatística Aplicada. (2010). Sistema de Indicadores de Percepção Social: Cultura. IPEA. 17p. URL: http://www.ipea.gov.br/portal/index. php? option $=$ com_content $\&$ view $=$ article $\&$ id $=2$ 4426\&catid $=120 \& \overline{\text { Itemid }}=2$. Acesso 10.07.2020.

Instituto do Patrimônio Histórico e Artístico Nacional. 
(2018). Lista de bens tombados e processos em andamento (1938-2018). IPHAN, 2018. URL: http://portal. iphan.gov.br/uploads/ckfinder/arquivos/Lista $\% 20$ de\%20Processos\%20de\%20Tombamento.pdf. Acesso 10.07.2020.

Conselho Internacional de Museus. (2007). Definition of museum. ICOM. URL:https://icom.museum/en/ activities/standards-guidelines/museum-definition/. Acesso 18.11.2020.

Leiva, J., \& Meirelles, R. (2018). Cultura nas capitais: com 33 milhões de brasileiros consome diversão e arte. Rio de Janeiro: 17 Street Produção Ed. URL: https://static.poder360.com.br/2018/07/10810_Livro_Web. pdf. Acesso 10.07.2020.

Mano, S., Cazelli, S., Costa, A. F., Damico, J. S., Silva, L. C., Curz, W. S., \& Guimarães, V. F. (2017). Museus de ciências e seus visitantes: estudo longitudinal - 2005, 2009, 2013. Rio de Janeiro: Fundação Oswaldo Cruz / Casa Oswaldo Cruz / Museu da Vida.

Mano, S. M. F. \& Damico, J. S (Org.). (2017). Viajando com o Ciência Móvel. Caderno Museu da Vida, 6. Rio de Janeiro: Fundação Oswaldo Cruz / Casa Oswaldo Cruz / Museu de Vida.

Mansur, K. L. (2009). Projetos educacionais para popularização das Geociências e para a geoconservação. São Paulo, Geol. USP, publ. esp., 5, 63-74.

Paula, L. M., Ruizb, A. S., Pereira, G. R., Andrade, V. A., Coutinho-Silva, R., \& Kurtenbach, E. (2014).
Um sábado de grandes descobertas: um olhar acerca dos Sábados da Ciência do Espaço Ciência Viva no Rio de Janeiro. Latin American Jornal of Science Education, 1, 22011-1-22011-14.

Ponciano, L. C. M. O., Castro, A. R. S. F., Machado, D. M. C., Fonseca, V. M. M., \& Kunzler, J. (2011). Patrimônio Geológico-Paleontológico in situ e ex situ: Definições, vantagens, desvantagens e estratégias de conservação. In: Carvalho, I. S., Srivastava, N. K., Strohschen, O., \& Lana, C. C. (Eds.) (2011). Paleontologia: Cenários de Vida. Río de Janeiro: Interciência, v. 4, p. 853-869.

Schobbenhaus, C., \& Silva, C. R. (2012). Geoparques do Brasil: propostas. Rio de Janeiro: SGB/CPRM.

Silva, R. G. P. (2020). Patrimônio geológico ex situ e estudo do seu potencial de divulgação cienífica no Museu da Geodiversidade (MGeo/IGEO/UFRJ). Rio de Janeiro: Instituto de Geociências UFRJ. 146p. (Dissertação de Mestrado).

Silva, R. G. P., Mansur, K. L., \& Castro, A. R. S. F. (2020). Consolidação da Geodiversidade como Patrimônio e o Valor Geológico dos Monumentos do Rio de Janeiro. Anuário do Instituto de Geociências, 43(3), 488-497. doi: 10.11137/2020_3_488_497

Van Geert, F. (2020). Entre < < géo-patrimonologie > > et meséologie géopatrimoniale: enjuex théoriques pour um futur muséal. ICOFOM Study Series, 48(1), 193-206. 